\title{
Epidemiology of HIV infection
}

\author{
MICHAEL W. ADLER, MD, FRCP \\ Professor of Genito-Urinary Medicine, Academic Department of Genito-Urinary Medicine, \\ University College and Middlesex School of Medicine, London
}

\section{A new disease}

In mid-1981 reports started to appear of cases of Pneumocystis carinii pneumonia (PCP) and of Kaposi's sarcoma (KS) amongst homosexual men in Los Angeles, California and New York [1-5]. This complex of diseases was subsequently termed the acquired immune deficiency syndrome (AIDS). The original working definition devised by the Centers for Disease Control (CDC) in 1982 was limited. It was modified after the discovery of the aetiological agent with the last and substantial change occurring in September 1987 [6]. The term AIDS now includes human immunodeficiency virus (HIV) encephalopathy, HIV wasting syndrome and a wider range of diseases indicative of AIDS. Also, in certain circumstances it permits the inclusion of cases without evidence of HIV infection or with laboratory evidence against HIV infection.

By March 1988 approximately 82,000 cases had been reported worldwide, 55,000 from the United States, 10,000 from Europe and nearly 10,000 from Africa. The notification system varies in different countries and continents, thus in some countries or regions there is undernotification. In Europe it is projected that there will be 30,000 cases by the end of 1988 and in the USA 270,000 cases by 1991. In America the doubling time for cases initially was approximately five to six months, but has now slowed down to about 10 months for all cases. Within the United States there are considerable geographical variations. The total rate per million for all cases of AIDS within the USA is 140, however in New York, San Francisco and Miami the rates are much higher (991, 966 and 584 respectively), where cases have occurred particu-

Table 1. AIDS in adult patient groups in the USA and UK, March 1988

\begin{tabular}{lrrrr}
\hline Patient groups & \multicolumn{2}{c}{ USA } & \multicolumn{2}{c}{ UK } \\
\cline { 2 - 5 } & No. & $(\%)$ & No. & $(\%)$ \\
\hline Homosexual men & 35577 & $(64)$ & 1123 & $(84)$ \\
Intravenous drug user & 9767 & $(18)$ & 23 & $(2)$ \\
Homosexual male and I.V. & & & & \\
$\quad$ drug user & 4114 & $(7)$ & 22 & $(2)$ \\
Haemophilia & 565 & $(1)$ & 80 & $(6)$ \\
Received blood & 1341 & $(2)$ & 27 & $(2)$ \\
Heterosexual contact & 2233 & $(4)$ & 47 & $(3.5)$ \\
Other/Miscellaneous & 1718 & $(3)$ & 9 & $(0.5)$ \\
Total & 55315 & $(100)$ & 1331 & $(100)$ \\
\hline
\end{tabular}

USA: Males $93 \%$; Females $7 \%$

UK: Males $97 \%$; Females $3 \%$ larly in homosexual men and intravenous drug abusers. In the UK the first cases were seen in 1983 and since then there has been an exponential rise with a doubling time of approximately 10-11 months. By March 1988, 55,315 adult cases had been reported from the USA and 1,331 from the UK (Table 1). The epidemiology in the USA and the UK is very similar and only varies in two aspects. Firstly, proportionately more homosexual men (84\%) have AIDS in the UK compared with the USA and secondly, the UK has experienced far fewer cases in total and proportionately among intravenous drug abusers. Otherwise, the epidemiology is essentially the same in both countries with cases predominantly occurring in men. In the USA, the proportion of patients notified in 1981 who are now dead is 84 per cent and 31 per cent of those notified in 1984. Median survival time after diagnosis varies with the manifestations of the disease and is approximately nine months for patients with PCP and 31 months for those suffering from $\mathrm{KS}$. In the UK the figures are similar with a mean survival of 12.5 months for patients with PCP and 21.2 months for those with $\mathrm{KS}$ [7].

\section{HIV prevalence}

The availability of an effective antibody test and access to stored samples of sera collected for other reasons on groups of homosexual men has given a clear indication of how the epidemic of HIV infection has developed. In San Francisco it has been possible to describe the unfolding epidemiology in detail (Table 2) [8]. In 1978, 4 per cent of homosexual men in a cohort study in San Francisco were found to be anti-HIV positive, by 1980 the proportion had increased six-fold to 24 per cent. It is interesting, however, to note that cases of AIDS did not start to develop until the seroprevalence had reached 24 per cent

Table 2. Estimate of number of individuals with HIV antibody and AIDS, 1978-1984 (San Francisce CDC Cohort Study $[n=6875])$

\begin{tabular}{|c|c|c|c|c|c|c|c|}
\hline Variable & 1978 & 1979 & 1980 & 1981 & 1982 & 1983 & 1984 \\
\hline Seropositive (\%) & 4 & 12 & 24 & $35^{*}$ & $46^{*}$ & $57^{*}$ & 68 \\
\hline $\begin{array}{l}\text { Estimated number } \\
\text { seropositive }\end{array}$ & 275 & 825 & 1650 & 2406 & 3162 & 3919 & 4675 \\
\hline $\begin{array}{l}\text { Cumulative number } \\
\text { reported with AIDS } \\
{ }^{*} \text { Estimated } \\
\text { Source: Curran } \text { et al. } 1985\end{array}$ & $\begin{array}{l}S \quad 0 \\
5[8]\end{array}$ & 0 & 2 & 14 & 41 & 84 & 166 \\
\hline
\end{tabular}


Table 3. Prevalence of anti-HTLV III in homosexual men attending departments of genito-urinary medicine

\begin{tabular}{|c|c|c|c|}
\hline Location & Year & Specimens $(n)$ & Prevalence (\%) \\
\hline \multirow[t]{3}{*}{ London } & 1982 & 107 & 3.7 \\
\hline & 1984 & 124 & 21.0 \\
\hline & 1985 & 432 & 35.0 \\
\hline \multicolumn{4}{|c|}{5 Provincial } \\
\hline \multirow[t]{2}{*}{ centres } & 1984 & 955 & 5.1 \\
\hline & 1985 & - & 11.0 \\
\hline \multicolumn{4}{|c|}{$\begin{array}{l}\text { Source: Carne et al. } 1985 \text { [9], Mortimer et al. } 1985 \text { [10], Jesson et al. } \\
1986 \text { [11]. }\end{array}$} \\
\hline
\end{tabular}

and therefore it would seem that the proportion of individuals infected needs to be high before cases of AIDS start to become apparent. This underlines the importance of health education campaigns early on when the seroprevalence is still low. In the UK a similar increase in seroprevalence has been seen amongst homosexual men (Table 3). In 1982, random samples [8] of homosexual men coming to a London STD clinic showed that just under 4 per cent were infected, but by 1984 this had reached 21 per cent in the same clinic [9]. Outside London the epidemic has been less obvious but the seroprevalence is increasing as witnessed by a doubling of the seroprevalence in patients coming to departments of genito-urinary medicine between 1984 and 1985 [10, 11].

Among intravenous drug abusers, the seroprevalence varies considerably within and between countries (Table 4) [12]. Within the USA, particularly high rates occur in New York City and Northern New Jersey, much lower rates in New Orleans, Washington and San Francisco. In Europe, the seroprevalence varies considerably, with high rates, for example, in Southern Italy, Spain and Edinburgh, and much lower rates in European countries such as Denmark, Sweden, Yugoslavia and England. It is interesting to note that Glasgow, only 50 miles from Edinburgh, has a very low rate indeed.

\section{Heterosexual transmission}

Case reports and surveys indicate that the virus can be transmitted from men to women and from women to men, as well as homosexually. Heterosexual transmission rates vary widely. For example, the proportion of female partners of male patients with AIDS or HIV infection who have become seropositive as a result of sexual exposure ranges from 22 to 73 per cent [13-18]. The different rates depend, to some extent, on different study designs and on the stage of the disease of the index case entered into the study. However, there is no doubt that this virus can be spread by the sexual route between heterosexuals. In the USA 7 per cent and in the UK 3 per cent of cases have occurred among women and even though in the States the commonest risk factor for acquisition of HIV amongst women is through intravenous drug abuse, the next most common mode of transmission is heterosexual contact. Guinan and Hardy [19] have found a steadily rising proportion of women who have acquired AIDS through heterosexual contact.
Table 4. HIV seroprevalence among intravenous drug users in the USA* and Western Europe

Location Date

(a) USA

High seroprevalence: $50 \%$ or higher

Manhattan, NYC

Northern New Jersey

1984

1984

Moderate seroprevalence: $20-49 \%$

Bronx, New York

1985

Boston

1985

Low seroprevalence: $5-19 \%$

Chicago

1984

San Francisco

1985

Washington DC

1985

Very low seroprevalence: less than $5 \%$, but greater than $1 \%$

New Orleans

Southern New Jersey

1985

1984

(b) Western Europe

High seroprevalence: $50 \%$ or greater

Southern Italy

1985

Spain

1985

Edinburgh, Scotland

1985

Moderate seroprevalence: $20-49 \%$

Berlin, FDR

1985

Zurich, Switzerland

1985

Amsterdam, Holland

Dublin, Ireland

1985

1985

Low seroprevalence: 5-19\%

Copenhagen, Denmark

1985

Stockholm, Sweden

1985

Very low seroprevalence: less than $5 \%$ but greater than $0 \%$

Yugoslavia

1985

Glasgow, Scotland

*Source: Des Jarlais and Friedman, 1987 [12]

1985

Table 5. Temporal trends in AIDS in women in the USA, 1982-November 1986

\begin{tabular}{|c|c|c|c|c|c|}
\hline \multirow{2}{*}{$\begin{array}{l}\text { Transmission } \\
\text { category }\end{array}$} & \multirow[b]{2}{*}{1982} & \multicolumn{3}{|c|}{ Cases (\%) } & \multirow[b]{2}{*}{1986} \\
\hline & & 1983 & 1984 & 1985 & \\
\hline $\begin{array}{l}\text { Intravenous drug } \\
\text { user }\end{array}$ & 47 & 59 & 56 & 52 & 48 \\
\hline $\begin{array}{l}\text { Heterosexual } \\
\text { contact }\end{array}$ & 14 & 14 & 17 & 20 & 26 \\
\hline $\begin{array}{l}\text { Born in country } \\
\text { with heterosexual } \\
\text { transmission }\end{array}$ & 18 & 8 & 6 & 5 & 5 \\
\hline Transfusion & 8 & 7 & 8 & 11 & 10 \\
\hline $\begin{array}{l}\text { Undetermined } \\
\text { Source: Guinan and Hardy }\end{array}$ & $\begin{array}{c}14 \\
1987[19\end{array}$ & 12 & 12 & 11 & 10 \\
\hline
\end{tabular}

Originally, in 1982, 14 per cent had acquired it in this fashion, but this has risen to 26 per cent while all other transmission categories have stayed virtually unchanged (Table 5).

\section{A heterosexual epidemic?}

Such an epidemic exists in Africa. It is extremely difficult to know whether it will occur within the USA and UK or 
whether the virus, once it has got into the heterosexual population, will be maintained at a very low endemic level. The crucial information required to make any judgment about the potential for a heterosexual epidemic is the amount of partner change that occurs in the heterosexual population. May and Anderson [20] have pointed out that the mean number of partner change in cohorts of homosexual men in the USA and UK is very high and this amount of partner change is ideal for sustaining and driving forward a sexually transmitted disease. In contrast, there is very little knowledge of the amount of partner change occurring in the heterosexual population. For example, one Harris poll on a sample of 822 individuals would suggest there is minimal partner change. If this is confirmed in a larger and more scientifically sound survey, then the potential for HIV to become a heterosexual disease would be considerably modified.

Homosexual men in the UK have modified their behaviour. Studies carried out at the Middlesex Hospital show that there was originally a very rapid rise in seroprevalence between 1982 and 1984 amongst homosexual men attending the department of genito-urinary medicine but that at the beginning of 1986 the seroprevalence flattened off at 25 per cent and has remained at this level twelve months later [21]. In parallel, the rate of gonorrhoea in homosexual men has dropped dramatically from 15 to 5 per cent. Similar changes in syphilis have been described in the USA [22]. In San Francisco changing sexual practices have been reported in homo-

\section{References}

1. Gottlieb, M. S., Schanker, H. M., Fan, P. T. et al. (1981) Morbidity and Mortality Weekly Report, 30, 250.

2. Friedman-Kien, A., Laubenstein, L. and Marmor, M. (1981) Morbidity and Mortality Weekly Report, 30, 305.

3. Gottlieb, M. S., Schroff, R. and Schanker, H. M. (1981) New England Journal of Medicine, 305, 1425.

4. Hymes, K. B., Cheung, T. and Greene, J. B. (1981) Lancet, ii, 598.

5. Friedman-Kien, A,. Laubenstein, L. J. and Rubinstein, P. (1982) Annals of Internal Medicine, 96, 693.

6. Centers for Disease Control (1987) Morbidity and Mortality Weekly Report, Supplement $1 \mathrm{~S}$.

7. Marasca, G. and McEvoy, M. (1986) British Medical Journal, 292, 1727.

8. Curran, J. M. C., Morgan, W. M., Hardy, A. M. et al. (1985) Science, 229, 1352.

9. Carne, C. A., Weller, I. V. D., Sutherland, S. et al. (1985) Lancet, i, 1261 .

10. Mortimer, P. P., Jesson, W. J., Vaudervelde, E. M. and Pererra, M. S. (1985) British Medical Journal, 290, 1176.

11. Jesson, W. J., Thorp, R. W., Mortimer, P. P. and Oates, J. K. (1985) Lancet, i, 155.

12. Des Jarlais, D. C. and Friedman, S. R. (1987) AIDS, 1, 67.

13. Peterman, T. A. Stoneburner, R. L. and Allen, J. R. (1986) Paper presented at II International Conference on AIDS, Paris. sexual men. The survey was carried out between August 1984 and April 1985 [23] by random telephone interviewing and it indicated that more men had entered a monogamous or celibate relationship over this time interval and less were having more than one partner. Changes in sexual practices have also been observed in a cohort of 100 men in London. There was a reduction in the number of partners and trends towards safe sex practices. Condom usage had increased but not to a statistically significant degree [24].

\section{Conclusion}

The number of cases of AIDS in developed and developing countries will continue to rise for some years to come since they represent infection acquired in the early 1980 s. Thus, the recent changes in sexual behaviour amongst homosexual men in the UK and the USA, even though encouraging, will not be translated into a slowing down of the epidemic for some years. Due to the lack of data on the sexual behaviour of heterosexuals it is not possible to judge or estimate whether an epidemic will occur among heterosexuals in developed countries as it has in continents such as Africa.

This article is based on a paper delivered at a Conference on Neuropsychiatric Disease and AIDS held at the Royal College of Physicians of London in October 1987.

14. Redfield, R. R., Wright, D. C. and Markham, P. D. (1986) Paper presented at II International Conference on AIDS, Paris.

15. Steigbigel, N. H., Maude, D. W. and Feiner, C. J. (1987) Paper presented at III International Conference on AIDS, Washington.

16. Taelman, H., Bonneux, L. and Cornet, P. (1987) Paper presented at III International Conference on AIDS, Washington.

17. Fischl, M. A., Dickinson, G. M., Scott, G. B. and Klimes, N. (1987) Journal of the American Medical Association, 257, 640.

18. Padian, N., Marquis, L. and Francis, D. P. (1987) Journal of the American Medical Association, 258, 788.

19. Guinan, M. E. and Hardy, A. (1987) Journal of the American Medical Association, 257, 2039.

20. May, R. M. and Anderson, R. M. (1987) Nature, 326, 137.

21. Carne, C. A., Weller, I. V. D., Johnson, A. M. et al. (1987) Lancet, i, 656 .

22. Judson, F. N. (1983) Lancet, ii, 59.

23. Centers for Disease Control (1985) Morbidity and Mortality Weekly Report, 34, 613.

24. Carne, C. A., Weller, I. V. D., Sutherland, S. et al. (1985) Lancet, i, 1261 .

Further reading

Adler, M. W. (Ed) (1987) ABC of AIDS: Articles published in the BMJ.

London: British Medical Journal. 